УДК 159.97

\title{
МЕТОДОЛОГИЧЕСКАЯ «ВИЛКА» В ДЕТСКОЙ НЕЙРОПСИХОЛОГИЧЕСКОЙ КОРРЕКЦИИ
}

\author{
Цветков Андрей Владимирович \\ д.псх.н., профессор \\ научный руководитель \\ ООО «Центр нейропсихологии Изюминка»
}

\begin{abstract}
Аннотация: Работа посвящена обсуждению методологического противоречия в нейропсихологической коррекции развития детей. В первую очередь дошкольного возраста. Это противоречие состоит в высоких ожиданиях клиента (семьи ребенка) и низком наличном уровне развития. В необходимости включать в работу кору головного мозга при ее сниженной активации и загруженности решением задач подкорковых структур (в порядке компенсации). Разрешить парадокс предлагается ориентацией коррекции на формирование разных уровней ориентировки, от рефлекса до самосознания и субъектности от схемы тела до личности.
\end{abstract}

Ключевые слова: Нейропсихология детского возраста, методологический парадокс, смысловой подход, сенсо-моторная коррекция.

\section{METHODOLOGICAL OPPOSITION IN CHILDREN'S NEUROPSYCHOLOGICAL CORRECTION}

\section{Tsvetkov Andrey Vladimirovich}

\begin{abstract}
Methodological contradiction in the children's development neuropsychological correction is discussed. Meaning, first of all, preschool age. This contradiction consists of the client's (the child's family) high expectations and the low current level of development. Then, the need of brain cortex's switching on with its reduced activation and the workload of subcortical structures problems solving (in order of compensation). It is proposed to solve the paradox to focus the correction on the formation of different levels of orientation, from reflex to selfconsciousness and subjectivity from the body scheme to the personality.
\end{abstract}


Key words: Developmental neuropsychology, methodological paradox, semantic approach, sensorimotor correction.

Одной из основных проблем нейропсихологии является методологический кризис [1]. Причем стоит отметить, что за два десятка лет с момента утверждения такового кризиса Л.С. Цветковой изменения если и произошли, то не в лучшую сторону.

Так, основатель отечественной нейропсихологии А.Р. Лурия [2] определял ее как «науку о мозговой организации высших психических функций (ВПФ)». Достаточно амбициозно по задачам, но все же с четко ограниченным предметом. ВПФ, по Л.С. Выготскому [3], базово имеют характеристики осознанности, произвольности и опосредования. Это позволяло, с одной стороны, отделить сферу компетенции от неврологии, где многие синдромы связаны с неосознаваемыми и/или неподконтрольными произвольно процессами. С другой стороны, от психиатрии, которая на тот период времени в большей степени занималась чисто психическими изменениями нежели их «привязкой» к работе мозговых структур.

Текущая ситуация связана с взаимопроникновением указанных областей знания, плюс коррекционная педагогика и психолингвистика.

Что кажется более существенным, это изменение объектов внимания нейропсихологии. Место локальных поражений головного мозга давно на периферии научного поиска. Сосудистые (нелокальные), диффузные (дегенеративные, постгипоксические и постинфекционные, постпсихотические изменения в ткани мозга) и нарушения развития.

На последних стоит остановиться особо. Во-первых, победа человечества над естественным отбором в виде антибиотиков и вакцин резко снизила силу «отбраковки нежизнеспособных». Соответственно, должен был произойти дрейф генов, изменение частоты встречаемости аллелей. Те варианты генов, которые еще сто лет назад сочетались с повышенной смертностью, стали более частотными. Не будет натяжкой предположение, что такие варианты существуют во всем многообразии человеческого генома, включая интимно связанные с центральной нервной системой и еe физиологией. Во-вторых, успехи акушерства, неонаталогии и микропедиатрии позволяют сейчас массово выхаживать детей, рожденных с экстремально низким весом (от 500 гр.). Вырос и процент медикаментозно сохраняемых беременностей, стали обыденностью дети, рожденные при помощи 
вспомогательных репродуктивных технологий (низкая фертильность, как известно, один из инструментов «дарвиновского» отбора), огромная часть родов осуществляется с разными видами стимуляции (окситоцин, «механика», вакуум-экстракция) или кесаревым сечением.

На изначальное нездоровье накладываются аутоиммунные реакции, повышенная уязвимость к инфекциям, в т.ч. нейротропным (герпес-вирусы), неадекватные стратегии адаптации взрослых к особенностям ребенка.

В итоге к 3 годам, когда дети попадают в сферу компетенции нейропсихолога, они уже сильно «зашумлены» сочетанием различных патофизиологических факторов, попыток их лечения (часто несогласованных, разнонаправленных и не слишком фармакологически грамотных).

Это не просто «диффузная» патология головного мозга. Нередко сочетание последствий объективных повреждающих ЦНС факторов, ставших по М.К. Мамардашвили и А.М. Пятигорскому [4] «превращенной формой», суммирующей неврологию, ошибки воспитания и невротические реакции самого ребенка.

Такая «превращенная форма» обычно дает рассогласование объективно наблюдаемых феноменов, скажем, повреждения перивентрикулярного белого вещества и поведенческих, крайне часто, по типу дофаминового дефицита (гиперкинезы, нарушения потребностной сферы, искажения уровня бодрствования). Здесь также стоит обратить внимание на абсолютное доминирование синдромов поражения или дисфункции стволовых подкорковых структур в текущей детской популяции.

Системная патология развивающейся психики вызывает к жизни совершенно неконкретные или неадекватные состоянию запросы клиентов (семьи детей). Уверен, мало кто из коллег сочтет вопрос по поводу четырехлетки «в нормальную-то школу пойдем?» четким целевым ориентиром. Его можно интерпретировать как запрос на нормализацию (а иногда так и говорят, «когда Вася станет нормальным?»), но на таком фундаменте цели, задачи и последовательность коррекции строятся плохо. Примером неадекватных запросов является сосредоточение клиента на одном каком-нибудь значимом познавательном процессе, чаще на речи. Несформированность чувственной базы речи - психомоторики, предметного восприятия, эмоций, просто не берется в расчет.

Речь при этом во внутренней картине болезни ребенка у его родителей понимается как инструмент социализации, «чтобы мог играть с другими 
детками», «чтобы понимал меня и воспитателя», «чтобы научился вести себя прилично».

В конечном итоге, от нейропсихолога ждут решения «поведенческих» задач. Связанных с регуляторными процессами на разных уровнях нервной системы (1) и со знаковым, в основном речевым, «овладением собой» (по Выготскому) (2).

Думается, не стоит напоминать о принципе прогрессивной кортикализации А.Р. Лурия [2], заключающемся во все большей передаче контроля за всеми аспектами психики в кору головного мозга по мере развития. Обратной стороной этого принципа является большой вес непроизвольных и неопосредованных знаково-символически компонентов ВПФ у детей. Дополняется лурьевский принцип прогрессивной кортикализации наблюдением Н.А. Бернштейна [5] об автоматизации любого осваиваемого навыка, передаче контроля за фоном движений и действий нижележащим (подкорковым) структурам. Что должно сопровождаться смещением фокуса произвольного внимания на цели, а не состав действия.

Перед нами классическая «вилка»: функциональная слабость древних мозговых структур, принципы работы которых заданы эволюционноинстинктивно дает низкую активацию коры и необходимость включения коркового контроля над самыми простыми действиями, начиная с передвижения в пространстве. Низкая нейропластичность (или, по Н.П. Бехтеревой [6], жесткость) ствола и подкорки не позволяет надеяться на быстрое «освобождение» коры от несвойственных ей функций и перевод корковых отделов в режим догоняющего освоения знаково-символических компонентов ВПФ.

Это противоречие на текущий период предлагается снимать двумя путями. Первый наиболее широко известен как «метод замещающего онтогенеза» (Семенович А.В. [7]) или сенсо-моторная коррекция. Пафос подхода состоит в многократной отработке движений, обеспечиваемых в норме определенными отделами ствола мозга с выходом на приемлемый уровень компенсации. Второй имеет название «смысловой нейропсихологии» [8] и ориентирует практиков на преодоление дефицита исполнительных операций (движений, перцепций, ориентировок) через создание специальной предметной среды (Цветков А.В. [9]) и/или же диктующего поведение сюжета занятия. 
Не останавливаясь на сильных и слабых сторонах каждого из подходов скажем, что их нередко смешивают, проводя нейропсихологическую коррекцию в эклектической методологии. Классическим «диагностическим» признаком специалиста-эклектика является словосочетание «нейропсихологические упражнения для... (аутистов, гиперактивных, безречевых и т.д.)». Фактически, вместо нейропсихологии занимаются натаскиванием и формированием не ВПФ, но навыков. Адача, бесспорно, важная. Однако навык или даже система навыков не требуют вообще наличия каких бы то ни было ВПФ! Дрессированное животное может владеть десятками усвоенных условно-рефлекторно навыков (сидеть, лежать, фас, дай лапу у собак). Но ни осознанности, ни произвольности, ни опосредствования, конечно, в поведении животных нет.

Навык как цель работы присутствует в олигофренопедагогике, изначально предполагающей неплохо прогнозируемый «потолок» в достижениях ребенка.

А ведь большинство обращений сейчас идут от семей, дети в которых не имеют грубой органической патологии мозга! И «потолок» их развития предугадать или сложно, или, в дошкольном возрасте, почти невозможно.

Поэтому подмена задачи видится не только методологической ошибкой, но и этической.

Снять противоречие «низкого старта» и высоких задач в работе нейропсихолога автором работы предлагается следующим путем:

1. в качестве оперативных задач коррекционной работы рассматривать формирование разных уровней ориентировки, от ориентировочного рефлекса до полноценной исследовательской деятельности - это одна из сквозных линий развития психики, проявляющаяся от рефлексов новорожденности до сложнейших форм мышления;

2. в качестве «субстрата» для ориентировки разного уровня рассматривать последовательно схему тела, первичный Я-образ (означенная и частично осознанная схема тела), первично-социальное «Я» (Я-образ, вписанный в окружающее предметное и социальное пространство через потребности, эмоции, и общение с другими), личность (первично-социальное «Я», овладевшее в некоторой степени планированием и временной перспективой). Каждой из этих стадий развития субъектности соответствует определенный нейропсихологический синдром. 
Таким образом, с одной стороны, получается составить некоторые «наборы упражнений» для каждого подкоркового синдрома, не вдаваясь в решение методологического вопроса о первичности работы над инстинктивно заданными или сознательными процессами. С другой стороны, худших черт эклектической ориентации в виде нерефлексии целей и различия метода и упражнений в рамках метода, такой подход лишен.

Понимая небольшую востребованность работ, затрагивающих методологические проблемы в нейропсихологии, тем не менее, надеемся на продуктивные размышления коллег и открытый диалог с ними.

\section{Список литературы}

1. Цветкова Л.С. Афазиология: современные проблемы и пути их решения. - М.: МПСИ, 2011. - 744c.

2. Лурия А.Р. Основы нейропсихологии. - М. : Издательский центр «Академия», 2013. - 384 с.

3. Выготский Л.С. Основы дефектологии. - С-Пб.: Лань, 2003 - 654 с.

4. Мамардашвили М.К., Пятигорский А.М. Символ и сознание. - М.: Языки русской культуры, 1997. - 224 с.

5. Бернштейн Н.А. Физиология движений и активность. - М.: Книга по Требованию, 2012. - $496 \mathrm{c}$.

6. Бехтерева, Н. П. Здоровый и больной мозг человека. - М.: АСТ, 2009. $-399 \mathrm{c}$.

7. Семенович А.В. Нейропсихологическая коррекция в детском возрасте. Метод замещающего онтогенеза: учебное пособие. - М.: Генезис, 2007. - 479 c.

8. Перегуда С.Н., Реброва Е.А. Нейропсихология смысла. - М.: Издание книг. ком, 2021. - 200с.

9. Цветков А.В. Нейропедагогика предметно-развивающей среды. - М.: Издание книг.ком, 2020. - 96с.

(C) А.В. Цветков, 2021 